\title{
Analisis Sentimen Terhadap Kenaikan Iuran Bpjs Kesehatan Pada Twitter Menggunakan Nä̈ve Bayes Classifier
}

\author{
Putri Dewi Wulandari ${ }^{1 凶}$, Ultach Enri $^{2)}$, Aji Primajaya ${ }^{3)}$ \\ ${ }^{112) 3)}$ Program Studi Teknik Informatika, Universitas Singaperbangsa Karawang, Indonesia \\ 1) putri.16166@student.unsika.ac.id \\ 2) ultachestaff.unsika.ac.id \\ 3) aji.primajaya@staff.unsika.ac.id
}

\begin{abstract}
Health service is one of the fundamental rights of the community whose provision must be carried out by the Government as mandated in the 1945 Constitution Article $28 \mathrm{H}$ Paragraph (1). According to the Presidium of the Indonesian Student Press Association Activist Alumni Forum, the National Health Insurance Program whose implementation is entrusted to the Health BPJS is far from the meaning of justice. One of the problems faced by the Health BPJS is the large number of participants who are in arrears in making payments, causing a huge deficit in the Health BPJS and causing the Government to officially raise BPJS Health contributions according to the Minister of Finance's proposal Sri Mulyani. The number of public complaints about government policy issues in raising BPJS Health fees, so this study was conducted with the aim of finding conclusions from public perceptions using the Naive Bayes Classifier algorithm with the TF-IDF selection feature. The dataset used as many as $\mathbf{3 5 6}$ data divided into two classes, namely positive and negative classes that have been through the selection phase by Indonesian Language Experts. The classification process produces the best accuracy results with a split ratio of 60:40 that is equal to $92.96 \%$ using the TF-IDF selection feature.
\end{abstract}

Keywords - Sentiment, Naive Bayes Classifier, BPJS Health, Text Mining, TF-IDF

Intisari - Pelayanan kesehatan merupakan salah satu hak mendasar masyarakat yang penyediaannya wajib diselenggarakan oleh Pemerintah sebagaimana telah diamanatkan dalam Undang-Undang Dasar 1945 Pasal 28 H Ayat (1). Menurut Presidium Forum Alumni Aktivis Perhimpunan Pers Mahasiswa Indonesia, Program Jaminan Kesehatan Nasional yang pelaksanaannya dipercayakan pada BPJS Kesehatan masih jauh dari makna keadilan. Salah satu persoalan yang dihadapi BPJS Kesehatan yaitu banyaknya peserta yang menunggak dalam melakukan pembayaran sehingga menimbulkan defisit yang sangat besar pada BPJS Kesehatan dan menyebabkan Pemerintah resmi menaikkan iuran BPJS Kesehatan sesuai usulan Menteri Keuangan Sri Mulyani. Banyaknya keluhan masyarakat terhadap isu kebijakan Pemerintah dalam menaikkan iuran BPJS
Kesehatan, maka dilakukan penelitian ini dengan tujuan untuk menemukan kesimpulan dari persepsi masyarakat menggunakan algoritma Naive Bayes Classifier dengan fitur seleksi TF-IDF. Dataset yang digunakan sebanyak 356 data yang terbagi kedalam dua kelas yaitu kelas positif dan negatif yang telah melalui tahap seleksi oleh Ahli Bahasa Indonesia. Proses klasifikasi menghasilkan hasil akurasi terbaik dengan ratio split 60:40 yaitu sebesar 92,96\% dengan menggunakan fitur seleksi TF-IDF.

Kata Kunci - Sentimen, Naive Bayes Classifier, BPJS Kesehatan, Text Mining, TF-IDF

\section{PENDAHULUAN}

Pelayanan kesehatan merupakan salah satu hak mendasar masyarakat yang penyediaannya wajib diselenggarakan oleh Pemerintah sebagaimana telah diamanatkan dalam UndangUndang Dasar 1945 Pasal 28 H Ayat (1) yang berbunyi "Setiap orang berhak hidup sejahtera lahir dan batin, bertempat tinggal, dan mendapatkan lingkungan hidup yang baik dan sehat serta berhak memperoleh pelayanan kesehatan" dan Pasal 34 Ayat (3) yang berbunyi "Negara bertanggung jawab atas penyediaan fasilitas pelayanan kesehatan dan fasilitas pelayanan umum yang layak" [1].

Salah satu persoalan yang dihadapi BPJS Kesehatan yaitu banyaknya peserta yang menunggak dalam melakukan pembayaran sehingga menimbulkan defisit yang sangat besar pada BPJS Kesehatan dan menyebabkan banyaknya keluhan masyarakat terhadap BPJS Kesehatan. Menurut Kepala Biro Komunkasi dan Layanan Informasi (Kepala Biro KLI) Kementerian Keuangan (Kemenkeu) Nufransa Wira Sakti mengklarifikasi diantara penyebab utama defisit program Jaminan Kesehatan Nasional (JKN) yang sudah terjadi sejak awal pelaksanaannya adalah besaran iuran yang underpriced dan adverse selection pada peserta mandiri. Pada akhir tahun anggaran 2018, tingkat keaktifan peserta mandiri hanya $53,7 \%$. Artinya, 46,3\% dari peserta mandiri tidak disiplin 
membayar iuran dengan kata lain menunggak. Sejak 2016 sampai dengan 2018, besar tunggakan peserta mandiri mencapai sekitar Rp. 15 triliun. Sepanjang 2018, total iuran dari peserta mandiri adalah Rp. 8,9 triliun, namun total klaimnya mencapai Rp. 27,9 triliun. Dengan kata lain, claim rasio dari peserta mandiri ini mencapai 313\%. Dengan demikian, seharusnya kenaikan iuran peserta mandiri lebih dari $300 \%$ [2].

Penelitian sebelumnya yang dilakukan oleh Raya, Nurbaiti, \& Sofia [3] tentang Klasifikasi Sentimen Masyarakat terhadap Kenaikan Harga Tiket Pesawat pada Twitter Menggunakan Naive Bayes. Hasil dari penelitian ini adalah kenaikan harga tiket pesawat dapat di klasifikasi dengan baik ke dalam bentuk positif dan negatif. $62 \%$ masyarakat mengangap kenaikan harga tiket pesawat sebagai hal yang biasa saja., 16\% memberikan tanggapan positif dan $22 \%$ memberikan tanggapan negatif. Akurasi data latih Naive Bayes yaitu sebesar $100 \%$ dan K-Nearest Neighbor Classifier sebesar $73,33 \%$. Untuk akurasi data uji Naive Bayes yaitu sebesar 90,70\% dan K-Nearest Neighbour Classifier sebesar $62,79 \%$. Dari hasil penelitian tersebut dapat disimpulkan bahwa algoritma Naive Bayes menghasilkan akurasi yang lebih tinggi dibandingkan KNN.

Text mining merupakan suatu proses pengetahuan intensif antara pengguna yang berinteraksi dan bekerja dengan sekumpulan dokumen atau data dengan menggunakan beberapa peralatan untuk menganalisis [4]. Text mining atau text analytics merupakan istilah yang biasa digunakan dalam mendeskripsikan sebuah teknologi yang mempu menganalisis data teks semi-terstruktur maupun tidak terstruktur. Adapun perbedaan data mining dengan text mining adalah data mining mengolah data yang bersifat terstruktur sedangkan text mining mengolah data atau dokumen semi-terstruktur maupun tidak terstruktur [5].

Algoritma Naive Bayes Classifier adalah algoritma yang mengklasifikasikan turunan dari teorema Bayes yang sederhana. Algoritma Naive Bayes Classifier digunakan untuk mencari nilai probabilitas tertinggi dalam mengklasifikasikan data testing pada kategori yang paling tepat. Algoritma Naive Bayes Classifier memiliki keunggulan yang sederhana, cepat, dan tingkat akurasi yang cukup tinggi daripada algoritma klasifikasi lainnya. Dalam penelitian ini yang menjadi data testing adalah dokumen test digital dari media sosial, yaitu tweet dari pengguna Twitter. Naive Bayes Classifier mengasumsikan bahwa keberadaan maupun ketidakberadaan sebuah fitur dalam sebuah kelas tidak memiliki keterkaitan dengan keberadaan maupun ketidakberadaan fitur lainnya [6]. Secara umum teorema Bayes dapat dinotasikan pada persamaan sebagai berikut:

$$
P(A \mid B)=\frac{P(A \mid B) P(A)}{P(A)}
$$

Peluang kejadian A sebagai $\mathrm{B}$ ditentukan dari peluang $\mathrm{B}$ saat $\mathrm{A}$, peluang $\mathrm{A}$ dan peluang $\mathrm{B}$. $\mathrm{P}(\mathrm{A} \mid \mathrm{B})$ memiliki arti yaitu peluang A jika diketahui keadaan $\mathrm{B}$.

Confusion matrix adalah suatu tabel untuk mengukur kinerja algoritma klasifikasi atau model klasifikasi atau classifier. Pada confusion matrix terdapat beberapa istilah yang umum digunakan, yaitu antara lain sebagai berikut:

1. True Positives (TP) merupakan persentase dari kelas positif yang berhasil diklasifikasi sebagai kelas positif.

2. True Negatives (TN) merupakan persentase dari kelas negatif yang berhasil diklasifikasi sebagai kelas negatif.

3. False Positives (FP) merupakan kelas negatif yang diklasifikasi sebagai kelas positif.

4. False Negatives (FN) merupakan kelas positif yang diklasifikasi sebagai kelas negatif.

Term Frequency Inverse Document Frequency (TF-IDF) adalah sebuah metode yang digunakan untuk mengekstrak kalimat dengan cara memberikan nilai atau bobot pada kalimat. TF-IDF melakukan pembobotan terhadap kemunculan kata dalam suatu dokumen. TF menyatakan jumlah kata yang muncul dalam suatu dokumen. Sedangkan IDF menunjukkan tingkat kepentingan suatu kata yang terdapat dalam kumpulan dokumen. Pada penelitian sebelumnya nilai TF didapat dari nilai frekuensi kemunculan fitur t pada dokumen $\mathrm{d}$.

$$
\mathrm{TF}_{\mathrm{t}, \mathrm{d}}=\boldsymbol{f}(\boldsymbol{t}, \boldsymbol{d})
$$

\section{MetodoloGi}

Metodologi pada penelitian ini dengan mengikuti tahapan yang terdapat pada proses data mining yakni tahapan Knowledge Discovery in Database (KDD). Adapun alur atau tahapan dari KDD yakni sebagai berikut:

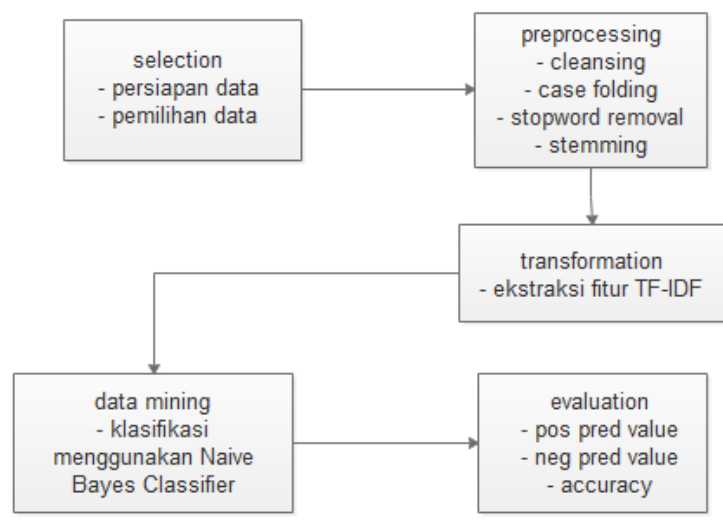

Gambar 1. Metodologi Penelitian

Pada Gambar 1 menjelaskan alur dalam pengolahan data yang akan di lakukan dalam penelitian ini yaitu:
1. Selection
2. Preprocessing
3. Transformation
4. Data Mining
5. Evaluation

\section{HASIL DAN PEMBAHASAN}

Data yang akan digunakan dalam proses klasifikasi sentimen terhadap kenaikan iuran BPJS Kesehatan pada twitter: 


\section{A. Selection}

TABEL 1. JUMLAH TWEET SENTIMEN KENAIKAN IURAN BPJS KESEHATAN HASIL SELEKSI

\begin{tabular}{|l|c|c|c|c|c|c|}
\hline Kata Kunci & Sept & Okt & Nov & Des & Jan & Feb \\
\hline \#bpjsnaik & 3 & 2 & & 3 & 8 & \\
\hline \#iuranbpjs & 2 & & & & & \\
\hline \#BoikotBPJS & & & 333 & 1 & 2 & 2 \\
\hline \multicolumn{7}{|c|}{ Total } \\
\hline
\end{tabular}

Berdasarkan Tabel 1 dapat dijelaskan bahwa dari 5.821 data tweet didapatkan 356 tweet yang diperoleh dari bulan september hingga bulan februari. Penentuan kelas sentimen pada setiap data komentar dilakukan secara manual oleh peneliti, kemudian dilakukan tahap validasi oleh Ahli Bahasa Indonesia yaitu Bapak Imam Muhtarom, S.S., M.Hum yang merupakan Dosen Pendidikan Bahasa dan Sastra Indonesia Universitas Singaperbangsa Karawang. Berikut merupakan data sentimen yang telah di seleksi oleh peneliti dan telah dilakukan validasi oleh Ahli Bahasa Indonesia:

\begin{tabular}{|l|l|}
\hline tweet & Label \\
\hline Kalo naik sampe 2kali lipat di seluruh indonesia sement... & Negatif \\
\hline Urus dulu @BPJSKesehatanRI boss, perbaiki manageme... & Negatif \\
\hline rakyat dikorbankan \#BoikotBPJS \#BPJSMenyusahkanRak... & Negatif \\
\hline Coba riset, survey dan buat laporan atas fakta dilapang... & Negatif \\
\hline Boikot aja bpjs, biarin ga bisa bikin sim. Jangankan dian... & Negatif \\
\hline Kt nya meringakan. Knp membebankan... Kita di bilang ... & Negatif \\
\hline \#BPJSnaik Pelayanan harus naik atau ditingkatkan. \#NKRI & Positif \\
\hline Jangan katakan apa yang bisa diberikan negara kepada ... & Positif \\
\hline yah dimaklumi tapi tetap & Positif \\
\hline Gw sangat tertolong sih ada bpjs kesehatan ini..100rb p... & Positif \\
\hline Harusnya bukan \#BoikotBPJS, tapi \#PerbaikiBPJS. Banya... & Positif \\
\hline Bangke emng mereka yg menaikan iuran BPJS demi kepe... & Negatif \\
\hline Rncana gue \#BoikotBPJS Kalian digajih utk mensejahtra... & Negatif \\
\hline biarin dah klo mau bangkrut juga \#BoikotBPJS & Negatif \\
\hline Pilih bpjs yg bangkrut atau rakyat yg bangkrut....? \#Bub... & Negatif \\
\hline Mau stop gak bisa, bubarkan saja BPJS. \#BubarkanBPJS ... & Negatif \\
\hline
\end{tabular}

Gambar 2. Data Tweet Hasil Seleksi Ahli Bahasa

Berdasarkan Gambar 2 dapat dijelaskan bahwa data yang berhasil diseleksi oleh Ahli Bahasa Indonesia dibagi kedalam dua kelas yaitu kelas sentimen positif dan kelas sentimen negatif dengan jumlah data sebanyak 356 data tweet sentimen yang terdiri dari 26 data tweet untuk kelas sentimen positif dan 330 data tweet untuk kelas sentimen negatif.

\section{B. Preprocessing}

Data sentimen yang telah melalui tahap seleksi oleh Ahli Bahasa Indonesia, kemudian dilakukan tahap preprocessing untuk menghilangkan kata yang kurang berpengaruh dalam proses pengklasifikasian. Berikut merupakan hasil dari preprocessing data yang akan dilakukan.

\section{Cleansing}

[4] pak seharusnya memastikan jon hanya melihat dr jenis pengobatannya saja tp tinjau kembali kerja
sama thdp RS Swasta apakah biaya yg dikenakan wajar atau tdk pelayanannya sesuat atau tdk [5] Terasa sekali bagi yg upahnya pas pasan kaya gini

[6] Saat tahun bergant $f$ nanti banyak masyarakat yang be]
ganti naik hingga Rakyat miskin tercekik dilarang sakit [7] Bagus saya gak jantungan gini hari dikabarin begini
ngangguran kaga cair cair Help pak pictwittercomzmsvuqou

[8] Gila gilaaaa dapat SMS dari BP]s per Januari Iuran BPJS naik GILAAAAKKK AING HAYANG CEURIK ceu [9] bila berkaitan dgn kenaikan iuran BP]s kesehatan oleh krnnya kami menolak dikarenakan jutaan da agar peruntukannya tepat $n$ tdk merugikan uang rakyat

\section{Gambar 3. Hasil Proses Cleansing}

Dari Gambar 3 dapat dijelaskan bahwa data yang sudah dilakukan proses cleansing sudah berhasil menghilangkan mention, hashtag, dan tanda baca (punctuation) yang tidak berpengaruh.

\section{Case Folding}

[4] pak seharusnya memastikan jon hanya melithat dr jents pengobatannya saja tp tinjau kembalt kerja
sama thdp rs swasta apakah biaya yg dikenakan wajar atau tdk pelayanannya sesuat atau tdk [5] terasa sekall bagi yg upahnya pas pasan kaya gin-

[6] saat tahun berganti nanti banyak masyarakat yang belum menyadari bahwa iuran bpjs juga akan ber
ganti naik hingga rakyat miskin tercekik dilarang sakit [7] bagus saya gak jantungan gini hari dikabarin beginian sementara tunggakan masih $\mathrm{rb}$ mana gaji pe
ngangguran kaga cair cair help pak pictwittercomzmsvuqou [8] gila gilaaaa dapat sms dari bpjs per januari iuran bpjs naik gilaaaakkk aing hayang ceurik ceu [9] bila berkaitan dgn kenaikan furan bpjs kesehatan oleh krnnya kami menolak dikarenakan jutaan da

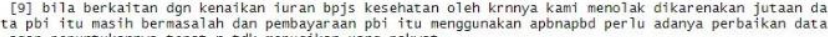
agar peruntukannya tepat $n$ tdk merugikan uang rakyat

\section{Gambar 4. Hasil Proses Case Folding}

Pada Gambar 4 telah melalui tahap cleansing dimana semua data telah diubah menjadi huruf kecil.

\section{Stopword Removal}

[4] seharusnya jgn dr jenis pengobatannya tp tinjau kerjasana thdp rs swasta biaya yg dikena kan wajar tdk pelayanannya sesuai tdk

[5] yg upahnya pas pasan kaya gint

[6] berganti masyarakat menyadari iuran bpjs berganti rakyat miskin tercekik dilarang s [7] bagus gak jantungan gini dikabarin tunggakan rb gaji pengangguran kaga cair cair pictwi tercomznsvuqued

[8] gila gila sms bpjs januari iuran bpjs gilak hayang ceurik dydydy

[9] berkaitan dgn kenaikan furan bpjs kesehatan krnnya menolak jutaan data pbi bermasalah pe bayaraan pbi apbnapbd perbaikan data peruntukannya $n$ tdk merugikan uang rakyat [10] tul makga bayar

Gambar 5. Hasil Proses Stopword Removal

Dari Gambar 5 dapat dijelaskan bahwa data yang telah melalui tahap stopword removal telah dibandingkan dengan kosa kata yang terdapat dalam kamus stopword. Stopword yang digunakan dalam setiap studi kasus dapat disesuaikan sesuai kebutuhan data penelitian.

\section{Stemming}

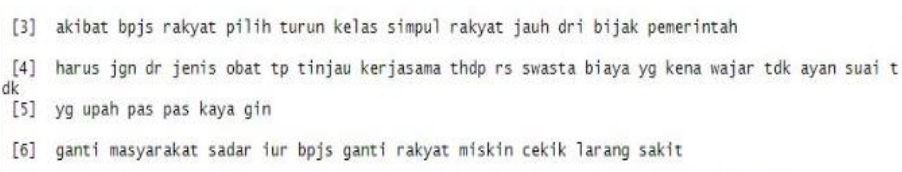

\section{Gambar 6. Hasil Proses Stemming}

Dari Gambar 6 dapat dijelaskan bahwa data tweet yang telah melalui tahap stemming merupakan data bersih yang sudah dihilangkan imbuhannya dan menjadi kata dasar sehingga dapat dilanjutkan ke tahap selanjutnya. 


\section{Transformation}

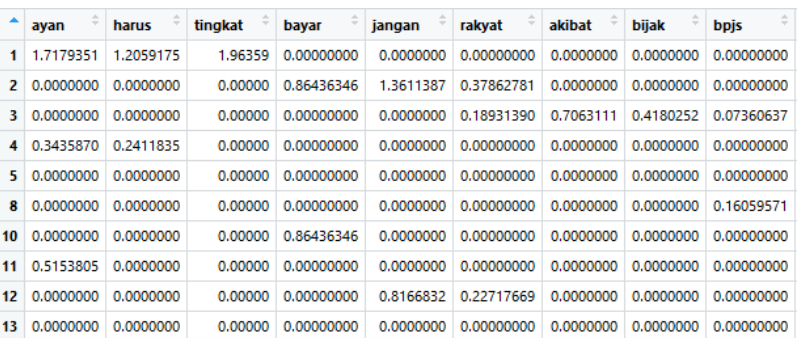

Gambar 7. Bobot Pada Data Training

Proses pembobotan dilakukan dengan membandingkan bobot setiap kata pada data testing dengan kata pada data training. Jika bobot probabilitas negatif lebih besar, maka hasil tweet tersebut kelas negatif. Namun, jika bobot probabilitas positif lebih besar, maka hasil tweet tersebut kelas positif.

\section{Data Mining}

Pada tahap data mining adalah tahap dilakukannya klasifikasi data teks menggunakan Naive Bayes Classifier. Pada penelitian ini dilakukan lima kali pengujian yaitu menggunakan persentase $90 \%$ data latih dan $10 \%$ data uji. Pengujian yang kedua menggunakan persentase $80 \%$ data latih dan $20 \%$ data uji. Pengujian ketiga menggunakan persentase $70 \%$ data latih dan $30 \%$ data uji. Pengujian keempat menggunakan persentase $60 \%$ data latih dan $40 \%$ data uji. Pengujian kelima menggunakan persentase $50 \%$ data latih dan 50\% data uji [7].

TABEL 2. PEMBAGIAN DATA LATIH DAN DATA UJI

\begin{tabular}{|c|c|c|c|}
\hline $\begin{array}{c}\text { Split } \\
\text { Ratio }\end{array}$ & $\begin{array}{c}\text { Persentase } \\
(\boldsymbol{\%})\end{array}$ & Data Latih & Data Uji \\
\hline 0,9 & $90 \%$ dan $10 \%$ & 320 & 36 \\
\hline 0,8 & $80 \%$ dan $20 \%$ & 285 & 71 \\
\hline 0,7 & $70 \%$ dan $30 \%$ & 249 & 107 \\
\hline 0,6 & $60 \%$ dan $40 \%$ & 214 & 142 \\
\hline 0,5 & $50 \%$ dan $50 \%$ & 178 & 178 \\
\hline
\end{tabular}

Berikut merupakan proses training dengan mengklasifikasikan data latih secara manual yang telah melalui proses preprocessing, yaitu sebagai berikut:

TABEL 3 DATA TRAINING

\begin{tabular}{|c|c|c|}
\hline Tweet & Fitur & Class \\
\hline Tweet 1 & $\begin{array}{l}\text { bpjs pemerasan sistem } \\
\text { kompeni }\end{array}$ & Negatif \\
\hline Tweet 2 & $\begin{array}{l}\text { boikot bpjs lintah darat } \\
\text { ngisepin darah rakyat }\end{array}$ & Negatif \\
\hline Tweet 3 & $\begin{array}{l}\text { pemaksaan bayar iur bpjs } \\
\text { radikal sampe pake tukang } \\
\text { tagih }\end{array}$ & Negatif \\
\hline Tweet 4 & $\begin{array}{l}\text { gotong royong tolong } \\
\text { sehat bantu sakit moga } \\
\text { lambung sadar }\end{array}$ & Positif \\
\hline Tweet 5 & $\begin{array}{l}\text { naik iur bpjs sehat jangan } \\
\text { pandang negatif banding } \\
\text { lurus tingkat kualitas sehat } \\
\text { moga }\end{array}$ & Positif \\
\hline
\end{tabular}

\begin{tabular}{|l|l|c|}
\hline Tweet 6 & $\begin{array}{l}\text { pasien sakit jantung rugi } \\
\text { kalo bayar uang obat } \\
\text { untung bpjs }\end{array}$ & Positif \\
\hline
\end{tabular}

Berdasarkan Tabel 3, maka dapat dibuat sebuah model probabilitas sebagai berikut:

$$
\begin{gathered}
\mathrm{P}\left(\mathrm{V}_{\mathrm{J}}\right)=\frac{\text { docs }_{\mathrm{j}}}{\text { training }}=\frac{3}{6}=0,5 \\
P\left(a_{\text {bpjs }} \mid V_{\text {negatif }}\right)=\frac{3+1}{18+42}=0,067 \\
P\left(a_{\text {bpjs }} \mid V_{\text {positif }}\right)=\frac{2+1}{28+42}=0,043 \\
P\left(a_{\text {pemerasan }} \mid V_{\text {negatif }}\right)=\frac{1+1}{18+42}=0,033 \\
P\left(a_{\text {pemerasan }} \mid V_{\text {positif }}\right)=\frac{0+1}{28+42}=0,014 \\
P\left(a_{\text {sistem }} \mid V_{\text {negatif }}\right)=\frac{1+1}{18+42}=0,033 \\
P\left(a_{\text {sistem }} \mid V_{\text {positif }}\right)=\frac{0+1}{28+42}=0,014 \\
P\left(a_{\text {kompeni }} \mid V_{\text {negatif }}\right)=\frac{1+1}{18+42}=0,033 \\
P\left(a_{\text {kompeni }} \mid V_{\text {positif }}\right)=\frac{0+1}{28+42}=0,014
\end{gathered}
$$

\section{E. Evaluation}

Berdasarkan percobaan diatas dapat dijelaskan bahwa hasil akurasi menggunakan algoritma Naive Bayes Classifier dengan seleksi fitur TF-IDF maka didapatkan model dengan nilai accuracy $92,70 \%$.

Berikut merupakan hasil akurasi terhadap klasifikasi sentimen kenaikan iuran BPJS Kesehatan, yaitu sebagai berikut:

TABEL 4. TABEL AKURASI MODEL KLASIFIKASI
\begin{tabular}{|c|c|c|c|}
\hline $\begin{array}{c}\text { Rasio } \\
\text { Split }\end{array}$ & Accuracy (\%) & $\mathbf{9 5 \%}$ CI & $\begin{array}{c}\text { Rentang } \\
\text { CI }\end{array}$ \\
\hline $50: 50$ & $92,70 \%$ & $0,8783: 0,9605$ & 0,08220 \\
\hline $60: 40$ & $92,96 \%$ & $0,8743: 0,9657$ & 0,09140 \\
\hline $70: 30$ & $92,52 \%$ & $0,8580: 0,9672$ & 0,01092 \\
\hline $80: 20$ & $92,96 \%$ & $0,8433: 0,9767$ & 0,01334 \\
\hline $90: 10$ & $91,67 \%$ & $0,7753: 0,9825$ & 0,02072 \\
\hline
\end{tabular}

Berdasarkan Tabel 4 dapat dijelaskan bahwa terdapat lima skenario pembagian data training dan data testing dengan hasil yang telah ditunjukkan pada Tabel 4 yaitu pada rasio split 60:40 merupakan hasil dengan akurasi tertinggi sebesar 92,96\% dengan rentang kelebaran CI (Confidence Interval) lebih sempit dibandingkan dengan rasio split 80:20 [8].

Berdasarkan hasil seleksi yang dilakukan oleh Ahli Bahasa Indonesia, data sentimen terhadap kenaikan iuran BPJS Kesehatan berjumlah 356 tweet yang terdiri dari 330 tweet negatif dan 26 tweet positif. 


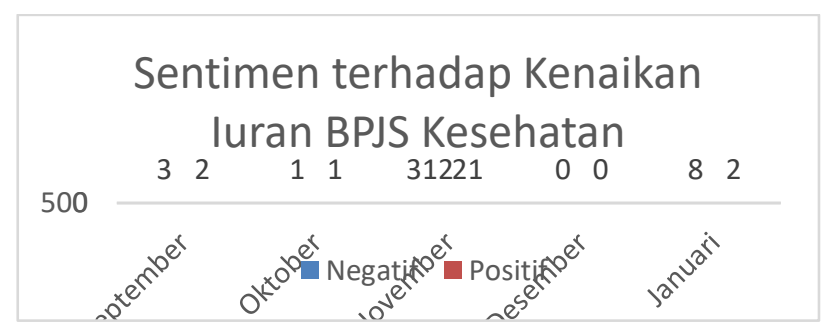

Gambar 8. Bobot Pada Data Training

Berdasarkan grafik pada Gambar 8 dapat dijelaskan bahwa data tweet sentimen terhadap kenaikan iuran BPJS Kesehatan lebih dominan terhadap kelas sentimen negatif dengan total data sentimen negatif yaitu sebesar 330 tweet yang tersebar pada bulan September, Oktober, November, dan Januari dimana tweet terbanyak ada pada bulan November yaitu sebesar 312 tweet sentimen negatif. Sedangkan tweet sentimen positif hanya terdapat 26 data tweet dengan populasi terbanyak ada pada bulan November yaitu 21 tweet.

Klasifikasi data sentimen terhadap kenaikan iuran BPJS Kesehatan pada twitter menggunakan Naive Bayes Classifier dilakukan dengan lima pengujian dan mendapatkan akurasi tertinggi pada rasio split 60:40 sebesar 92,96\% dengan pembagian data yakni 71 data uji dan rentang kelebaran $95 \%$ CI (Confidence Interval) sebesar 0,0914 yang menghasilkan presisi cukup baik [8] karena memiliki rentang lebih sempit dibandingkan dengan pengujian pada rasio split 80:20.

Secara keseluruhan dapat disimpulkan bahwa algoritma Naive Bayes Classifier pada penelitian ini menghasilkan akurasi yang tinggi.

\section{KESIMPULAN}

Berdasarkan hasil penelitian yang telah dilakukan terdapat kesimpulan yaitu Analisis sentimen terhadap kenaikan iuran BPJS Kesehatan dilakukan dengan membagi data yang telah melewati tahap preprocessing menjadi data latih dan data uji.

Pengujian dilakukan sebanyak 5 kali dengan persentase $90 \%$ data latih dan $10 \%$ data uji, $80 \%$ data latih dan $20 \%$ data uji, $70 \%$ data latih dan $30 \%$ data uji, $60 \%$ data latih dan $40 \%$ data uji, dan $50 \%$ data latih dan $50 \%$ data uji. Hasil klasifikasi 320 data latih dan 36 data uji menggunakan Naive Bayes Classifier dengan seleksi fitur TF-IDF pada Rstudio didapatkan 33 data kelas sentimen negatif diprediksi benar sebagai kelas sentimen negatif, sedangkan 3 data kelas sentimen positif diprediksi sebagai kelas sentimen negatif. Hasil akurasi terbaik merupakan klasifikasi menggunakan Naive Bayes Classifier dengan seleksi fitur TF-IDF yaitu sebesar $92,96 \%$ dengan persentase data sebanyak $60 \%$ data latih dan $40 \%$ data uji.

\section{ACKNOWLEDGMENT}

Alhamdulillah, segala puji serta syukur ke hadirat Allah SWT atas karunia dan rahmat-Nya sehingga penulis dapat menyelesaikan penelitian ini. Terima kasih kepada Universitas Singaperbangsa Karawang atas izin dan dukungan dalam proses penelitian ini. Serta terima kasih atas semua do'a, kasih sayang, nasihat, semangat serta dukungan dari Orang tua, keluarga dan sahabat yang telah di berikan sampai saat ini.

\section{REFERENCES}

[1] D. Septia, "Kepuasan Terhadap Kualitas Pelayanan BPJS Kesehatan," 19 Desember 2017. [Online]. Available: http://digilib.unila.ac.id.

[2] K. K. R. Indonesia, "Mengapa Iuaran BPJS Naik ?," 095 $\begin{array}{llll}\text { September } 2019 . & \text { [Online]. }\end{array}$ https://www.kemenkeu.go.id.

[3] A. M. Raya, F. Nurbaiti and D. Sofia, "Klasifikasi Sentimen Masyarakat terhadap Kenaikan Harga Tiket Pesawat pada Twitter Menggunakan Naive Bayes," Jurnal Instek, pp. 239246, 2019.

[4] R. Feldman and J. Sanger, The Text Mining Handbook Advanced Approaches In Analyzing Unstructured ed Data, New York: Cambridge University Press, 2007.

[5] H. N. Jamil, "Analisis Sentimen Pada Online Review Menggunakan Kombinasi Metode Lexicon Based dan Naive Bayes Classifier," Skripsi. Program Studi Statistika FMIPA UII Yogyakarta, Yogyakarta, 2017.

[6] A. Syakuro, "Analisis Sentimen Masyarakat terhadap ECommerce pada Media Sosial Menggunakan Metode Naive Bayes Classifier (NBC) dengan Seleksi Fitur Information Gain (IG)," Universitas Islam Negeri Maulana Malik Ibrahim, Malang, 2017.

[7] M. S. Simatupang, "Analisis Sentimen Pada Komentar Body Shaming Beauty Vlog Youtube," Karawang, 2019.

[8] N. Ms, "Estimasi-Confidence Interval," 2019. [Online]. Available: academia.edu. 